\title{
Differentiation Could Become the Next EU Integration Concept
}

On the occasion of the 60th anniversary of the Treaties of Rome came the latest step in what could become a climate change in European affairs, as the Rome Declaration was issued. The declaration formally recognised the concept of variable geometry - or in common terminology, a multispeed Europe - as an accepted means to further develop the European Union going forward. Earlier in March, the president of the European Commission, Jean-Claude Juncker, presented the White Paper on the Future of Europe, outlining five scenarios, one of which explicitly spelled out the prospect of groups of member states moving ahead on deeper integration. And already in the autumn of 2016, Angela Merkel had spent a fortnight consulting with leaders of select member states to build momentum for the Bratislava summit, which launched a "reflection process" on how to keep the EU together after the Brexit referendum.

These instances demonstrate a renewed desire to bring back to EU policymaking the strength that a unified political centre can provide. This centre would consist of a coalition of member states willing to shape and drive the EU agenda, to devise political initiatives and bring together the necessary majorities or consensus. Such a centre would also re-establish a strategic understanding among several member states about the importance of deeper cooperation, be it at the level of all member states or in a core group. It would counter the centrifugal tendencies inherent to the large and heterogeneous community of 28 - soon to be 27 - members.

The revival of coalition-building marks the end of a period in which the traditional clusters of EU members had withered away. For example, Italy had for years neglected the close cooperation which used to exist among the Inner Six; the Netherlands seemed less interested in the longestablished Benelux partnership; and the Visegrad Group of Poland, Hungary, the Czech Republic and Slovakia appeared to have lost its significance after the EU's eastern enlargement. Even the most essential of the traditional coalitions, the Franco-German tandem, was starting to creak. With the disappearance of these coalitions, the EU lost its political centre, and the EU institutions lacked the enabling support group of governments to back their initiatives.

Against this background, deeper interaction among EU states serves three main purposes. Firstly, forming coalitions is a tool of governance in a largely intergovernmental EU. At present, managing the status quo already requires significant member state interaction in advance of or around the formal procedures. With the large number of members, the need for informal consensus-building among governments has grown.

Secondly, coalitions offer the chance to counter the veto power which is now enjoyed by a large number of governments. Building consensus or even qualified majorities has become more complex due to the increased number of smaller member states. For the same reason, coalitions have become an instrument of majority building, representing clusters of consensus on different issues.

Thirdly, coalitions are a necessary building block of flexibility or differentiation of integration. In coalitions, strategic consensus and an operational strategy will be developed which would then be translated into enhanced cooperation under the treaties or core-building next to the EU's legal framework. Without their existence and formative impact, greater flexibility would likely result in a "Europe à la carte", in which member states opt out of policies as they please. "Differentiation" and "flexibility" have increasingly become code words for finding a way forward for an EU whose members appear deeply divided. The classic approach to "more Europe" is no longer an option, given the likely rejection of any significant treaty change in the ratification process. Instead, using the treaty clauses of "enhanced cooperation", first introduced by the Treaty of Amsterdam, or of "permanent structured cooperation", established for the area of security and defence by the Lis- 
bon Treaty, groups of member states have the option of moving ahead on their own and can thus overcome any lack of EU-wide consensus.

From the perspective of the EU institutions, the Juncker White Paper reflects the choices inherent in the aforementioned principle functions of member state coalition-building. Among other options, the paper lays out two conceptual alternatives for the EU. The first option is that the EU could focus on fewer issues but develop much deeper integration in areas such as border management, foreign policy and defence, while reducing its ambitions in other areas to securing the core functions of the single market and the common currency, leaving everything else to member states. As an alternative, the Commission suggests a scenario in which member states with ambitions for "more Europe" go ahead together, for example in internal security and justice or defence, with these groups also establishing separate common budgets.

The paper is remarkable in the sense that it does not follow the usual binary logic of progress versus decay. It assumes that the future could be a continuation of the present, but it also sees grounds for more regression towards a simple market place, which could lead to an unraveling of European integration. In this, the reasoning of the white paper suggests to prepare for change rather than to rely on the status quo.

Many governments in the south and east will feel uncomfortable with these alternatives, as they would prefer to stick to the status quo, while possibly repatriating some powers. They generally see the status quo delivering to them what they expect: financial support and political stability, economic growth and opportunity, but no interference in domestic affairs, and a continuation of the well-established role of Brussels as scapegoat for bad news. The prospect of regression or the emergence of an inner circle may scare them enough to consider deeper integration in some sectors. This might be just what the Commission had in mind when drafting the White Paper.

Governments in the economic and demographic centre will also not be enthusiastic. Their preference would also be a better functioning status quo, as this would carry less of the political risk implicit in change. In the political centres of the EU where the thinking about differentiation, multiple speeds or variable geometry has been advanced in light of the current crises, Juncker's scenarios will appear to restrict their ambitions by pointing explicitly to existing legal requirements. This would limit deeper integration to the requirements, rules and processes defined in the treaty clauses for "reinforced cooperation" or - in the area of defence - "permanent structured cooperation". Flexibility as defined by the treaties gives a decisive role to the European Commission in the establishment of avant-garde projects, requiring unanimity among member states. Thus, the conditionality of flexibility as currently defined may prevent it from being applied.

If and when initiatives for a sectoral deepening of integration in the EU are launched, they will therefore likely be modeled after the original Schengen Agreement of 1985, which was concluded by the five founding EU members as a treaty among them, separate from the European treaties but aiming to realise a goal stipulated by those treaties. The European Commission, headed by the long-time Prime Minister of Luxembourg, will certainly have had this example in mind when drafting the White Paper. Juncker's political sense may tell him that the Schengen example is the more inspiring and workable option. His role at the helm of the European Commission, however, would lead him to seek to prevent that particular road towards deeper integration from being taken.

At this critical juncture of European integration, member states' capacity and willingness to act together will shape the future of Europe. Cooperation among member states, the web of their interactions, and the patterns of like-mindedness and of strategic consensus have become factors key to keeping Europe together. But to continue using coalition-building for this purpose requires a deeper understanding of these factors. A simple return to traditional coalitions is not in the cards. New coalitions will need to be developed for the much larger EU of today, built on the interests, resources and transactional power of member states. 